\title{
Pediatric Myalgic Encephalomyelitis/Chronic Fatigue Syndrome
}

Leonard A. Jason ${ }^{1}$, Kristen Barker ${ }^{1}$, Abigail Brown ${ }^{1}$

1 Center for Community Research, DePaul University, Chicago, IL, USA

\section{Abstract}

Research on pediatric Myalgic Encephalomyelitis/Chronic Fatigue Syndrome (ME/CFS) is reviewed in this article. Many recent articles in this area highlight the existence of key differences between the adult and pediatric forms of the illness. This review article provides an overview of pediatric ME/ CFS, including epidemiology, diagnostic criteria, treatment, and prognosis. Challenges to the field are identified with the hope that in the future pediatric cases of ME/CFS can be more accurately diagnosed and successfully managed.

\section{Keywords}

Myalgic Encephalomyelitis/Chronic Fatigue Syndrome; Pediatrics; Diagnosis 


\section{Pediatric Myalgic Encephalomyelitis/ Chronic Fatigue Syndrome}

Myalgic Encephalomyelitis/Chronic Fatigue Syndrome (ME/CFS) is a protracted and persistent illness that produces a variety of debilitating effects in children and adolescents [1,2]. While a hallmark symptom of ME/CFS is profound fatigue, sufferers report a wide variety of concomitant symptoms including post-exertional malaise, body, myofascial and/or joint pain, cognitive difficulties, unrefreshing or disturbed sleep, headaches, and sore throat. Some symptoms are more common than others; however, the condition is characterized by unique symptom patterns and unpredictable symptom severity, which further complicates both treatment and prognosis [3].

Children and adolescents often present with symptoms that differ from their adult counterparts [4]. For example, stomachaches and rash are often reported in cases of pediatric ME/CFS, but are far less common in adults [2,3]. According to Bell [5], the three most common symptoms (aside from fatigue) in children with ME/CFS were headaches, sleep disturbance, and cognitive difficulties. Furthermore, children and adolescents may exhibit symptoms in response to their unique day-to-day routine (i.e., trouble in school, loss of friends, dropping out of extracurricular activities, etc.), and, due to their stilldeveloping coping skills, are more apt to display irritability in response to the disease [2].

Dowsett and Colby [6] found ME/CFS to be the most common cause of prolonged medical leave from school among adolescents. In another study, Carter and colleagues [7] found that $55 \%$ of children with ME/CFS reported a decline in academic performance since illness onset and $80 \%$ indicated major reduction in extracurricular activities. Smith and colleagues [8] found that one third of adolescents with ME/CFS report severe restrictions of all activities and marked drops in school performance; some missed up to 80 days in a six-month period.

\section{Epidemiology}

Epidemiologic methods summarize information about the distribution of illnesses and allow investigators to make inferences about the importance of risk factors or even causal factors (e.g., smoking as a precursor to cancer). However, even if the specific cause of an illness or social condition is not known, epidemiologists can uncover associations between risk factors that can lead to important ways of understanding the etiology and maintenance of an illness [9]. If biased sampling methods such as the utilization of physician gatekeepers to identify cases of myalgic encephalomyelitis/chronic fatigue syndrome (ME/CFS) result in an over- or underestimate of the true prevalence rate, it may impede efforts to understand the nature of the condition. This error occurred with the first generation of adult ME/CFS prevalence studies. Reyes and colleagues[10] published epidemiologic research that portrayed ME/CFS as being relatively rare, affecting about 20,000 adults, and characterized patients as being European-American and middle to upper-class women. These findings supported the myth of ME/CFS as a "YUPPIE flu" disease. So as long as scientists and the public perceived ME/CFS as rare, those with this illness would be unlikely to receive the needed federal attention and community resources to develop a better understanding of this illness. This CDC epidemiologic study was based on a method that relied on physician referral of patients with ME/CFS [10]. However, if the physicians did not believe the illness existed, or if patients did not have a physician, many people with ME/CFS would not be referred to researchers or counted in prevalence surveys.

A second generation of adult prevalence studies involved a randomly selected group of individuals being telephoned and screened for symptoms of ME/CFS [11]. Those who were identified in the telephone screen as having several ME/CFS symptoms underwent a complete medical and psychiatric 
examination to determine whether they actually had ME/CFS. This study estimated that over 800,000 people had ME/CFS, and this illness was found to be more prevalent among people of color. This study [11] and others [12] that used community-based samples differed from the methods used in the earlier CDC study [10] whereby physicians determined who was referred as a possible ME/CFS case.

\section{Pediatric epidemiology}

ME/CFS, involving 6 or more months of fatigue and other symptoms [1,13,14], causes significant impairment to various aspects of children's and adolescents' lives including physical functioning, school attendance and performance, and extracurricular activities [15]. Krilov and colleagues [16] found that only $14 \%$ of adolescents with ME/CFS attended school regularly after onset. Dowsett and Colby [17] found ME/CFS to be the most common cause of prolonged medical leave from school among adolescents, and yet there are no rigorous pediatric community-based ME/CFS prevalence estimates. In a 25-year follow up of a sample of pediatric patients with ME/CFS, Brown, Bell, Jason, and Christos [18] found that those patients that had improved still showed significantly more impairment on 23 of the 25 outcomes evaluated compared to a healthy control group. This study indicates that even though some youth with ME/CFS over time will not meet diagnostic criteria for ME/CFS, they remain symptomatic and may not return to their premorbid level of functioning.

The prevalence of pediatric ME/CFS has been under dispute. No rigorous community-based epidemiologic study has been conducted in in the US or internationally. Accurate sampling and measurement have been at the heart of the debate among researchers. If medical personnel believe that pediatric ME/ CFS is a relatively rare disorder, then physicians might minimize or misinterpret the physical complaints of ME/CFS patients, leading to the mistrust and lack of communication that has been reported between patients and medical personnel. In the US, the CDC conducted a surveillance study [19] and estimated that, among adolescents aged 12-17, 2.7 per 100,000 had ME/CFS, indicating that ME/CFS was a relatively rare disorder among youth. A major limitation of this study and a comparable study in Australia [20] was that the samples were obtained through physician referral; therefore, members of the community that do not or cannot access medical care for their symptoms were not included. The CDC conducted another study involving referrals from school nurses from middle and high schools in Wichita, Kansas, and Reno, Nevada. An ME/CFS prevalence of 24.0 per 100,000 was found for the 12 to 17 year old age group [21]. As in other medical referral studies, the gatekeeper methodology, as well as reliance on previous diagnoses by physicians (rather than current evaluations), limited the validity of these findings. Another CDC study involved a community-based investigation conducted in San Francisco [21]. This study employed random digit dialing to households as a means of identifying children and adolescents with ME/CFS-like illness. In adolescents aged 12-17, 116.4 per 100,000 were diagnosed with ME/CFS-like conditions. Unfortunately, these self-reports were not confirmed with medical assessments. A final CDC prevalence study by Jones and colleagues [22] involved a random digit dialing survey of the residents of Wichita, Kansas. The prevalence of pediatric ME/CFS-like illness was 338 per 100,000. Because this study did not include a medical evaluation of the pediatric sample, the actual number of ME/CFS cases in that population could not be determined; only "ME/CFS-like" illness could be diagnosed. The same problem pertains to recent pediatric estimates generated in the Netherlands [23]. To date, existing studies of ME/CFS in youth have lacked the ability to rigorously estimate the overall prevalence of pediatric ME/CFS or examine risk factors for the illness.

\section{Diagnostics}

The Fukuda et al. criteria [13] identify cases of ME/CFS for an adult population and may not be appropriate to diagnose and identify children with this illness. Children experience different ME/CFS sym- 
ptomatology than adults, for example, more frequently reporting abdominal pain and rashes [24]. Furthermore, youth with ME/CFS may experience more day to day fluctuations in their symptom severity [25]. In 2006, the International Association of Chronic Fatigue Syndrome (IACFSME) developed a Pediatric ME/CFS case definition [1]. The pediatric ME/CFS case definition requires more specification of critical symptoms [1] than the Fukuda et al. criteria [6]. The symptom categories included fatigue, post-exertional malaise, unrefreshing sleep or disturbance of sleep quantity, pain (myofascial, joint, abdominal and/or head pain), two or more neurocognitive manifestations, and at least one symptom from two of the following three categories: autonomic manifestations, neuroendocrine manifestations, or immune manifestations.

In addition, to meet this pediatric ME/CFS case definition [1], the children must have the concurrent occurrence of the following classic ME/CFS symptoms, which must have persisted or recurred during the past three months of illness (symptoms may predate the reported onset of fatigue). Support for the inclusion of these symptoms emerged from Rowe and Rowe's [26] confirmatory factor analysis, which found muscle pain and fatigue, neurocognitive, abdominal, head and chest pain, neurophysiological, and immunological factors. We recommend using the Pediatric ME/CFS Questionnaire, which provides a way of gathering this information to help diagnose pediatric ME/CFS [1]. It is generally recommended that adolescents age 12 and older fill it out themselves, and parents can assist or fill it out for the children 11 and under. Some children might need to complete the questionnaire over several days if completion exacerbates the children's symptoms. It is important to rate each symptom for severity and frequency, and to operationalize criteria to meet the case definition. Using the question: "how much does this symptom bother you," for a symptom to meet criteria, it should be rated a 4 or higher on the following scale: 1 = no problem, $4=$ moderate problem, 7 = big problem. In regards to how often the child has the symptom, to meet criteria, a symptom would have to be rated a 4 or higher on the following scale: 1 = hardly ever, to $4=$ half of the time, to $7=$ always.

\section{Post-exertional malaise and/or post-exertional fatigue}

With activity (it need not be strenuous and may include walking up a flight of stairs, or as minimal as using a computer or reading a book), there must be a loss of physical or mental stamina, rapid/sudden muscle or cognitive fatigability, post-exertional malaise and/or fatigue and a tendency for other associated symptoms within the patient's cluster of symptoms to worsen. The recovery is slow, often taking 24 hours or longer.

\section{Unrefreshing sleep or disturbance of sleep quantity or rhythm disturbance}

These symptoms may include prolonged sleep (including frequent naps), disturbed sleep (e.g., inability to fall asleep or early awakening), and/or day/night reversal.

\section{Pain (or discomfort)}

These symptoms are often widespread and migratory in nature. There needs to be the occurrence of at least one symptom from the following: myofascial and/or joint pain, abdominal and/or head pain. Myofascial pain can include deep pain, muscle twitches, or achy and sore muscles. Pain, stiffness, or tenderness may occur in any joint but must be present in more than one joint without signs of inflammation. Children with abdominal and/or head pain may experience eye pain/sensitivity to bright light, stomach pain, nausea, vomiting, or chest pain. People with ME/CFS often describe headaches as localized behind the eyes or in the back of the head, and may include headaches localized elsewhere, including migraines.

Children must also experience two or more neurocognitive manifestations which can include: impaired memory (self-reported or observable disturbance in ability to recall information or events on a 
short-term basis), difficulty focusing (disturbed concentration may impair ability to remain on task, to screen out extraneous/excessive stimuli in a classroom, or to focus on reading, computer/work activity, or television programs), difficulty finding the right word, frequently forgetting what one wanted to say, absent mindedness, slowness of thought, difficulty recalling information, needing to focus on one thing at a time, trouble expressing thought, difficulty comprehending information, frequently losing train of thought, or experiencing new trouble with math or other subjects.

Finally, the child must experience at least one symptom from two of the following three categories:

- Autonomic manifestations: neurally mediated hypotension, postural orthostatic tachycardia, delayed postural hypotension, palpitations with or without cardiac arrhythmias, dizziness, feeling unsteady on the feet with disturbed balance and/or shortness of breath.

- Neuroendocrine manifestations: recurrent feelings of feverishness and cold extremities, subnormal body temperature and marked diurnal fluctuations, sweating episodes, intolerance of extremes of heat and cold, marked weight change, loss of appetite or abnormal appetite, worsening of symptoms with stress.

- Immune manifestations: recurrent flu-like symptoms, non-exudative sore or scratchy throat, repeated fevers and sweats, lymph nodes tender to palpitation--generally minimal swelling noted, new sensitivities to food, odors, or chemicals.

\section{Severe versus moderate categories}

We created a separate category for those who did not meet full criteria but were still symptomatic, and they were classified as Moderate ME/CFS Clinical. These adolescents need to have 3 or more months of fatigue and need to report four out of the five classic ME/CFS symptoms with frequency and severity ratings of moderate or severe (a rating of 4 or higher, on a scale of 1-7). In addition, for autonomic, neuroendocrine, and immune manifestations, adolescents need at least one symptom in any of these three categories, as opposed to one symptom from two of the three categories.

\section{Other categories}

The pediatric case definition for ME/CFS also diagnoses children and adolescents with subtype variations of ME/CFS for those who experience idiopathic chronic fatigue. One subtype is atypical ME/CFS, which is defined as 3 or more months of fatigue, but missing more than one classic ME/CFS symptom. It is also possible to receive a diagnosis of ME/CFS in remission, if they met full symptom criteria at one time but were not experiencing full symptomatology at the time of the study. Another category is pediatric ME/CFS-like illness, which is defined as meeting all classic ME/CFS symptom criteria, except for the 3 month duration. This diagnosis (ME/CFS-like) could also be given to a child or adolescent who has not undergone a medical evaluation.

The IACFSME working group created a new assessment tool, the DePaul Pediatric Health Questionnaire (DPHQ), which is a self-report measure of ME/CFS symptoms for children who are under the age of 18 years old. Several theorists recommended that the ME/CFS diagnostic process would be improved with the inclusion of symptom severity ratings because of the disparities in symptoms often found among patients with ME/CFS [27,28]. Consequently, the DPHQ measures the presence or absence of symptoms, and also the severity and frequency of the symptoms in six specific symptom domains. Thus, the DPHQ captures a more accurate assessment of pediatric ME/CFS symptoms and accounts for the heterogeneous nature of this illness.

A study by Jason and colleagues [1] compared the new diagnostic criteria for Pediatric ME/CFS [1] with the Fukuda et al. [6] criteria in a sample of adolescent patients with ME/CFS and controls. Physicians referred thirty-three children and adolescents as having pediatric ME/CFS and twenty-one healthy children and adolescents. The Fukuda et al. criteria were less sensitive than the Pediatric ME/ 
CFS criteria in identifying pediatric ME/CFS cases. Findings suggest the Fukuda et al. criteria are less effective than the Pediatric ME/CFS criteria in correctly diagnosing cases of pediatric ME/CFS.

In another study [29], using the same sample as Jason and colleagues [1], physicians specializing in pediatric ME/CFS referred thirty-three pediatric patients with ME/CFS and twenty-one youth without the illness. Those who met ME/CFS criteria were separated into severe and moderate categories. Significant differences were found for symptoms within each of the six major categories: fatigue, postexertional malaise, sleep, pain, neurocognitive difficulties, and autonomic/neuroendocrine/immune manifestations. In general, the results showed that participants who met the severe ME/CFS criteria reported the highest scores, the moderate ME/CFS group scored lower than severe, and the control group evidenced the lowest scores. Findings indicate that the Pediatric Case Definition for ME/CFS can distinguish between those with this illness and controls, and between those with severe versus moderate manifestations of the illness.

\section{Hypothalamic-Pituitary-Adrenal (HPA) Axis Dysfunction}

Cortisol serves as the main signaling hormone of the HPA axis. Dysregulation of glucocorticoid function is associated with ME/CFS [30-33]. Patients with ME/CFS have lower cortisol secretion [34], a pattern of glucocorticoid resistance [35], and a disruption or dysregulation of the expected diurnal cortisol pattern [36]. The presence of HPA axis dysregulation in adolescence may serve as a predictor of this illness [37]. For example, Miike and colleagues [38] found that cortisol secretion was reduced in a pediatric ME/CFS population in comparison to controls. In addition, prior adverse events can "prime" inflammatory responses, promoting excessive cytokine production in response to subsequent stressors [39]. Thus, prior life adversity may produce stable alterations in processes that regulate the inflammatory response to subsequent stress [40]. Attenuated decline of salivary cortisol concentrations across the day and increased IL-6 concentration, a key mediator of such inflammatory responses, have been associated with fatigue symptoms in ME/CFS [41]. Others have found higher levels of proinflammatory immune responses, including IL-8 [42] and TNF-alpha [43] for individuals with ME/ CFS versus controls.

Variance in the expression of genes associated with HPA axis function has been found to be associated with ME/CFS [44-46]. For example, Rajeevan and colleagues [47] found that those with certain cortisol regulatory mechanisms (i.e., a single nucleotide polymorphism in the glucocorticoid receptor (GR) gene) were at increased risk for ME/CFS. Others have also found differences in the expression of glucocorticoid receptor NR3C1 in individuals with ME/CFS as compared to controls [33]. This suggests that patients with ME/CFS may have decreased sensitivity to the effects of cortisol due to a down-regulation of this glucocorticoid receptor [35].

Those with ME/CFS demonstrated improvements in a clinical trial of hydrocortisone [48]. However, such therapies are not appropriate for long-term treatment due to adrenal suppression [49]. As other pharmacologic modalities have not been beneficial in providing consistent relief to those with ME/ CFS, it is important to investigate non-pharmacologic methods of influencing hormonal pathways.

\section{Treatment}

There have been several cognitive behavioral therapy (CBT) trials for children and adolescents with ME/CFS. In Great Britain, Chalder, Tong, and Deary [50] examined the effectiveness of CBT with families of 11-18 year olds. Treatment consisted of family face-to-face treatment sessions every 2 weeks, for up to 15 sessions. Of the 23 enrolled patients, 15 were rated as improved at the six-month follow- 
up. Positive findings were also obtained for Viner and colleagues' [51] outpatient multidisciplinary rehabilitative treatment involving graded activities, exercise programs, family sessions, and supportive care with 12-17 year-old adolescents with ME/CFS. In Australia, Denborough and colleagues [52] reported benefits from a 4-week multidisciplinary inpatient treatment program for 39 adolescents with ME/CFS. Physical functioning scores improved significantly following treatment, and were maintained at 6 months. In another study, Wright and colleagues [53] compared two treatment programs for adolescents with ME/CFS. Those randomly assigned to the pacing program showed little improvement in activity scores and deterioration in school attendance, whereas those provided a tailored, incremental rehabilitation program (emphasizing a gradual return to normal social activities and a gradual return to school) evidenced marked improvements in both activity and school attendance. Stulemeijer and colleagues [54] provided a randomized trial of cognitive behavior therapy to 10-17 year old adolescents with ME/CFS. Of the 36 assigned to the CBT condition, 29 completed postassessment measures and 33 of 35 in the waiting list control condition completed the post-assessment. The patients were provided ten sessions over a five-month period. Patients in the treatment condition reported significantly greater decreases in both fatigue severity and functional impairment. Further, school attendance increased significantly more for those in the CBT condition. Patients sustained benefits from the intervention at 2-year follow-up [55]. Unfortunately, these studies have not incorporated biological markers.

Negative patient reactions to health care services and providers might in part be explained by the types of interventions offered to individuals with this illness. While CBT has been applied to many medical and psychiatric problems, from pain to fibromyalgia to depression, its application to ME/CFS has been more controversial. This might be due to several of the components of CBT as practiced by some European investigators (e.g. [56,57]). Typical of the psychogenic view of ME/CFS is a research group from the Netherlands [58] who believe that these individuals attribute their symptoms to physical causes, are overly preoccupied by their physical limitations, and do not maintain regular activity. According to this model, these factors cause individuals with ME/CFS to be functionally impaired, implying that the central problem with patients experiencing this condition is a psychosomatic preoccupation with one's fatigue. Song and Jason [59] tested this model with individuals with ME/CFS, and found that it was not valid for those individuals. In addition, Price, Mitchell, Tidy, and Hunot [60] reviewed 15 studies of CBT with a total of 1,043 ME/CFS participants. At treatment's end, 40\% of people in the CBT group showed clinical improvement in contrast to only $26 \%$ in usual care, but changes were not maintained at a one- to seven-month follow-up when including people who had dropped out.

Patient reactions to CBT and graded exercise have been mixed. A survey of 2,338 ME and ME/CFS respondents [61] found that $26 \%$ felt their condition worsened after trying CBT, and graded exercise was felt to be the treatment that negatively impacted the most people. Results of other surveys conducted by the ME Association showed that, of those that had received graded exercise therapy, 33.1\% felt "much worse" and $23.4 \%$ judged themselves to be "slightly worse" [62]. Similarly, a survey of treated patients with ME/CFS found that $34 \%$ of those who tried graded exercise therapy perceived themselves to be worse [63].

The ability to employ an intervention that enables youth with ME/CFS to have more control over their environment may help normalize cortisol levels. There is evidence that this has occurred following a CBT intervention for adults with ME/CFS [64]. Unfortunately, in the Roberts et al. study [64], there was no control or comparison group, and only a pre- and post-intervention (CBT therapy) cortisol level test. Treatment studies in the ME/CFS area have rarely examined neuroendocrine and immune dysregulation. It is important to examine critical neuroendocrine pathways in adolescents with ME/ CFS at a time where other confounding conditions are minimized (e.g., long term use of multiple pharmacologic interventions, other medical illnesses). 
Pacing has been a rehabilitation practice used to help patients with a number of painful somatic conditions such as headaches [65]. Pacing has been defined as an approach that encourages patients to be as active as possible within the limits imposed by their illness [66,67]. While more minor symptoms are ignored, more serious symptoms such as onset of muscle weakness, dizziness, or a flu-like malaise indicate that their "limits" have been exceeded, and then patients can either rest or change to an activity involving different muscles [68]. Jason and colleagues [69] developed a randomized trial of nonpharmacologic interventions for ME/CFS, including CBT and pacing. About 100 patients with ME/ CFS were randomly assigned to four interventions in which they were provided 13 biweekly sessions with a trained nurse therapist. Baseline, post-treatment, and six- and twelve-month follow-up data were collected. Although there were some differences among the four types of interventions, overall, individuals demonstrated general improvement across interventions. Jason, Benton, and colleagues [70] divided this sample into two groups of patients: those who were able to keep expended energy close to available energy and those who were not successful at this task. Those who were able to stay within their "energy envelope" had significant improvements in physical functioning and fatigue severity. Findings suggest that helping patients maintain appropriate energy expenditures in coordination with available energy reserves can help improve functioning over time.

Utilizing the same sample, Brown, Khorana, and Jason [71] found that those who were within their "energy envelope" before treatment showed more improvement in physical functioning and fatigue compared with those outside of their "energy envelope." These findings suggest that an assessment of perceived available and expended energy could help guide the development of individualized, nonpharmacologic interventions for people with ME/CFS.

Table I summarizes pediatric ME/CFS treatment studies.

\begin{tabular}{|c|c|c|c|c|}
\hline Author, year [ref] & Sample & Design & Treatment & Results \\
\hline $\begin{array}{l}\text { Chalder et al., } \\
2002 \text { [50] }\end{array}$ & $\begin{array}{l}11-18 \text { year olds } \\
(n=23)\end{array}$ & Uncontrolled & $\begin{array}{l}\text { Family CBT- } \\
\text { bimonthly up to } \\
15 \text { sessions }\end{array}$ & $\begin{array}{l}15 / 23 \text { enrolled patients rated } \\
\text { as improved on functioning and } \\
\text { fatigue at } 6 \text {-month follow-up }\end{array}$ \\
\hline $\begin{array}{l}\text { Denborough et } \\
\text { al., } 2003 \text { [52] }\end{array}$ & $\begin{array}{l}13-19 \text { year olds } \\
(n=35)\end{array}$ & Uncontrolled & $\begin{array}{l}\text { Multidisciplinary } \\
\text { inpatient tx: } 4 \text { weeks }\end{array}$ & $\begin{array}{l}\text { Physical and emotional } \\
\text { functioning improved following } \\
\text { treatment, maintained at 6-month } \\
\text { follow-up }\end{array}$ \\
\hline $\begin{array}{l}\text { Stulemeijer et al., } \\
2004 \text { [54] }\end{array}$ & $\begin{array}{l}\text { 10-17 year olds } \\
(n=71)\end{array}$ & RCT & CBT: 10 sessions & $\begin{array}{l}\text { Tx group reported greater } \\
\text { decreases in fatigue severity and } \\
\text { functionality, greater increase in } \\
\text { school attendance at 5-month } \\
\text { follow-up }\end{array}$ \\
\hline $\begin{array}{l}\text { Viner et al., } \\
2004 \text { [51] }\end{array}$ & $\begin{array}{l}9-17 \text { year olds } \\
(n=48)\end{array}$ & $\begin{array}{l}\text { Non-randomized } \\
\text { trial }\end{array}$ & $\begin{array}{l}\text { Multidisciplinary } \\
\text { outpatient program } \\
\text { (graded activity, } \\
\text { exercise programs, } \\
\text { family sessions and } \\
\text { supportive care) OR } \\
\text { supportive care alone }\end{array}$ & $\begin{array}{l}\text { Program group: higher wellness } \\
\text { scores and school attendance } \\
\text { compared to supportive care } \\
\text { group; } 43 \% \text { of program group } \\
\text { recovered compared to } 4.5 \% \text { of } \\
\text { supportive care group }\end{array}$ \\
\hline $\begin{array}{l}\text { Wright et al., } \\
2005 \text { [53] }\end{array}$ & $\begin{array}{l}11-19 \text { year olds } \\
(n=13)\end{array}$ & $\begin{array}{l}\text { Randomized } \\
\text { feasibility study }\end{array}$ & $\begin{array}{l}\text { Adaptive pacing } \\
\text { OR incremental } \\
\text { rehabilitation }\end{array}$ & $\begin{array}{l}\text { Adaptive pacing: non-significant } \\
\text { improvements. Rehabilitation } \\
\text { group: marked improvements in } \\
\text { activity and school attendance }\end{array}$ \\
\hline
\end{tabular}

Table I. Summary of pediatric ME/CFS treatment studies 


\section{Prognosis}

Given the lack of effective treatments available, the prognosis for children and adolescents with ME/ CFS tends to be poor [72]. While previous research suggests that young sufferers of ME/CFS have a better prognosis than their adult counterparts [75], a recent study disputes this idea. Brown and colleagues' [72] research examined long-term health outcomes of 25 people who were diagnosed with ME/ CFS while they were adolescents, approximately 25 years ago. Researchers assessed whether participants maintained their ME/CFS diagnosis, as well as current levels of health and functioning. Of the 25 participants diagnosed with ME/CFS 25 years ago, only five self-reported maintaining a diagnosis, while 20 reported remission from the disease. In spite of their self-reported remission, those 20 participants showed significantly more impairment compared to controls, demonstrating that, while adolescents diagnosed with the disorder may show some improvements over time, they still suffer some level of impairment and may not return to their premorbid level of functioning.

Further support for Brown and colleagues' [72] findings is seen in Joyce, Hotopf, and Wessely's [74] review of longitudinal ME/CFS studies. They found that fewer than $10 \%$ of adult participants across studies reported returning to premorbid functioning. A more recent review found a median ME/CFS recovery rate of 5\%, although there was variability in recovery rates across studies [73]. These findings highlight both the vastly debilitating nature of the disease, as well as the need for further longitudinal research in this area [72].

\section{Discussion}

Clearly, there is a need to examine the prevalence of pediatric ME/CFS in a community-based sample, as well as the relative frequency of ME/CFS among various groups (e.g., different age groups, genders, racial/ethnic groups, and socioeconomic strata) and to compare these samples to ones generated from community controls. Regrettably, because of the lack of community-based samples of pediatric ME/ CFS, it is not possible to describe basic characteristics of pediatric patients with this illness. Arav-Boger and Spirer [75] describe the usual pediatric patient as being previously athletic and ambitious, upper middle-class, and having close relatives with ME/CFS. In some ways, these findings resemble how adults with ME/CFS were described following the first generation of epidemiologic studies. Yet these data and other studies on youth with ME/CFS [76-78] may be misleading as they are based primarily upon patients seen in pediatric or adolescent clinics. Children and adolescents with ME/CFS may be misdiagnosed or undiagnosed, have limited access to healthcare, or have a physician who discounts their symptoms, and, thus, may not be included in such studies [79]. In addition, characteristics from adult ME/CFS samples might not apply to youth, as children may experience different symptoms than adults with ME/CFS [77]. Symptoms such as rashes, abdominal pain, and orthostatic intolerance (OI) symptoms may be frequently present in pediatric ME/CFS but are not as common in adults. At the present time, the most basic sociodemographic characteristics of pediatric ME/CFS in the general population have not been reliably identified. A variety of socio-environmental and psychological risk factors associated with ME/CFS onset and maintenance over time in adults (i.e., female gender, older age, minority status, lower socioeconomic status (SES), and higher fatigue severity [29]) need to be studied with a pediatric ME/CFS sample. It is also important to identify whether there are any associations with a variety of predisposing and precipitating risk factors (e.g., exposure to mononucleosis; immunizations; first, second and third degree relatives' ME/CFS and health status; psychiatric status, etc.) and pediatric ME/CFS in a community-based sample.

Non-pharmacologic rehabilitative interventions are used for people with cancer and heart disease, but they are only one component of the treatment plan, and, when used by themselves, are not curative. 
Future directions for research

Future studies should aim to establish the prevalence rate of pediatric ME/CFS using a community-based sample, rather than relying on physician referral. An appropriately conducted epidemiology study would permit researchers to examine the sociodemographic characteristics of those suffering from pediatric ME/CFS, describe the basic characteristics of these individuals with regards to symptom patterns and functionality, and to identify potential risk factors of the illness. This information will ultimately support researchers in establishing efficacious treatments/illness management strategies for pediatric ME/CFS.
Comprehensive approaches are also needed for patients with ME/CFS, and helping patients manage their illness non-pharmacologically is only one aspect of rehabilitation. Historically, researchers have focused on the potential benefits of cognitive behavioral interventions. As discussed, the long-term outcomes of this type of intervention are still unclear, but interventions that challenge basic patient illness beliefs might solidify already negative attitudes of medical personnel toward people with ME/CFS. The Energy Envelope Theory represents an alternative approach for helping patients, as it helps patients better monitor energy levels, stay within their energy envelopes, sustain lifestyle changes that involve reprioritizing activities, and possibly rebalance their lifestyle between work and leisure.

The review in brief

\begin{tabular}{|ll}
$\begin{array}{l}\text { Type of review } \\
\text { Literature search }\end{array}$ & PabMed with following keywords: pediatric ME/CFS, therapy, management, diagnostic criteria \\
Purpose & $\begin{array}{l}\text { The present article aims to review the existing literature on pediatric ME/CFS. Current research } \\
\text { findings on epidemiology, diagnosis and prognosis, biological markers of the illness, and treatments are } \\
\text { presented. Findings indicate that adult and pediatric ME/CFS represent distinct entities, and are both } \\
\text { poorly understood }\end{array}$ \\
Conclusions & $\begin{array}{l}\text { A lack of rigorous prevalence studies in this area limits the validity of current prevalence estimates; a } \\
\text { pediatric case definition has been demonstrated to accurately distinguish between children with ME/ } \\
\text { CFS and controls; prognosis for children with ME/CFS is poor, and while health may improve, returning } \\
\text { to pre-morbid functioning is rare; evidence of HPA axis dysfunction in adults with ME/CFS may } \\
\text { translate to pediatric populations; more research is needed on non-pharmacologic and pharmacologic } \\
\text { interventions for pediatric patients with ME/CFS but pacing strategies may be promising for this patient } \\
\text { population }\end{array}$ \\
Limitations & $\begin{array}{l}\text { Pediatric ME/CFS is an under-researched and poorly understood illness. Thus, the present review paper } \\
\text { is limited in scope as there is a dearth of information about the condition }\end{array}$ \\
\hline
\end{tabular}

\section{References}

1. Jason LA, Bell DS, Rowe K, et al. A pediatric case definition for ME/CFS. JCFS 2006; 13: 1-44; http://dx.doi.org/10.1300/J092v13n02_01

2. Jason L, Porter N, Shelleby E, et al. Examining criteria to diagnose ME/CFS in pediatric samples. Journal of Behavioral Health and Medicine 2010; 3: 186-195

3. Jason LA, Porter N, Shelleby E, et al. A case definition for children with Myalgic Encephalomyelitis/chronic fatigue syndrome. Clinical Medicine: Pediatrics 2008; 1: 53-7

4. Lapp, CW. Recognizing pediatric ME/CFS in the primary care practice: a practicing clinician's approach. JCFS 2007; 13: 89-96; http://dx.doi.org/10.1300/J092v13n02_06 
5. Bell DS. Diagnosis of chronic fatigue syndrome in children and adolescents: special considerations. JCFS 1995; 1: 29-66; http://dx.doi.org/10.1300/J092v01n03_05

6. Dowsett EG, Colby J. Chronic fatigue syndrome in children: Journal was wrong to criticize study in school children. BMJ 2007; 315: 949; http://dx.doi.org/10.1136/bmj.315.7113.949

7. Carter BD, Edwards JF, Kronenberger WG, et al. Case control study of chronic fatigue in pediatric patients. Pediatrics 1995; 95: 179-86

8. Smith MS, Mitchell J, Corey L, et al. Chronic fatigue in adolescents. Pediatrics 1991; 88: 195-202

9. Jason LA, Porter N, Rademaker, A. Epidemiologic approaches to community-based research. In: Jason LA \& Glenwick DS (eds). Methodological approaches to community-based research. Washington, DC: American Psychological Association, 2011

10. Reyes M, Gary Jr. HE, Dobbins JG, et al. Descriptive epidemiology of Chronic Fatigue Syndrome: CDC surveillance in four cities. Morbidity and Mortality Weekly Report Surveillance Summaries 1997; 46: 1-13

11. Jason LA, Richman JA, Rademaker AW, et al. A community-based study of chronic fatigue syndrome. Arch Intern Med 1999; 159: 2129-37

12. Reyes M, Nisenbaum R, Hoaglin DC, et al. Prevalence and incidence of chronic fatigue syndrome in Wichita, Kansas. Arch Intern Med 2003; 163: 1530-6; http://dx.doi.org/10.1001/archinte.163.13.1530

13. Fukuda K, Straus SE, Hickie I, et al. The Chronic Fatigue Syndrome: a comprehensive approach to its definition and study. Ann Intern Med 1994; 121: 953-9

14. Reeves WC, Lloyd A, Vernon SD, et al. Identification of ambiguities in the 1994 chronic fatigue syndrome research case definition and recommendations for resolution. BMC Health Services Research 2003; 3: 25; http://dx.doi.org/10.1186/1472-6963-3-25

15. Torres-Harding SR, Jordan K, Jason LA, et al. Psychosocial and physical impact of chronic fatigue syndrome in a community-based sample of children and adolescents. JCFS 2006; 13: 55-73; http:// dx.doi.org/10.1300/J092v13n02_03

16. Krilov LR, Fisher M, Friedman SB, et al. Course and outcome of chronic fatigue in children and adolescents. Pediatrics 1998; 102: 360-6; http://dx.doi.org/10.1542/peds.102.2.360

17. Dowsett EG, Colby J. Chronic fatigue syndrome in children: Journal was wrong to criticize study in school children. BMJ 2007; 315: 949; http://dx.doi.org/10.1136/bmj.315.7113.949

18. Brown M, Bell DS, Jason LA, et al. Understanding the prognosis of Myalgic Encephalomyelitis/ Chronic Fatigue Syndrome. J Clin Psychol [in press]

19. Gunn WJ, Connell DB, Randall B. Epidemiology of Chronic Fatigue Syndrome: The Centers for Disease Control study. In: Bock G. \& Whelan J. (eds). Chronic Fatigue Syndrome. New York: Wiley, 1993

20. Lloyd AR, Hickie I, Boughton CR, et al. Prevalence of chronic fatigue syndrome in an Australian population. The Medical Journal of Australia 1990; 153: 522-8

21. Dobbins JG, Randall B, Reyes M, et al. The prevalence of chronic fatiguing illnesses among adolescents in the United States. JCFS 1997; 3: 15-27; http://dx.doi.org/10.1300/J092v03n02_03

22. Jones JF, Nisenbaum R, Solomon L, et al. Chronic fatigue syndrome and other fatiguing illnesses in adolescents: A population-based study. Journal of Adolescent Health 2004; 35: 34-40

23. Nijhof SL, Maijer K, Bleijenberg G, et al. Adolescent chronic fatigue syndrome: Prevalence, incidence, and morbidity. Pediatrics 2011; 127: 1169-75; http://dx.doi.org/10.1542/peds.2010-1147

24. Jordan KM, Kolak AM, Jason LA. Research with children and adolescents with chronic fatigue syndrome: methodologies, designs, and special considerations. JCFS 1997; 3: 3-13; http://dx.doi. org/10.1300/J092v03n02_02 
25. Carruthers BM, Jain, AK, De Meirleir K, et al. Myalgic Encephalomyelitis/Chronic Fatigue Syndrome: Clinical working case definition, diagnostic and treatment protocols. JCFS 2003; 11: 7-36; http://dx.doi.org/10.1300/J092v11n01_02

26. Rowe KS, Rowe, KJ. Symptom patterns of children and adolescents with chronic fatigue syndrome. In: Singh NN, Ollendick TH, Singh AN (eds). International Perspectives on Child and Adolescent Mental Health. Kuala Lumpur: Elsevier Science Ltd., 2002

27. Jason LA, King CP, Frankenberry EL, et al. Chronic fatigue syndrome: Assessing symptoms and activity level. J Clin Psychol 1999; 55: 411-24; http://dx.doi.org/10.1002/(SICI)10974679(199904)55:4<411::AID-JCLP6>3.0.CO;2-N

28. King CP, Jason LA. Improving the diagnostic criteria and procedures for chronic fatigue syndrome. Biological Psychology 2005; 68: 87-106; http://dx.doi.org/10.1016/j.biopsycho.2004.03.015

29. Jason L, Porter N, Shelleby E, et al; Severe versus moderate criteria for the New Pediatric Case Definition for ME/CFS. Child Psychiatry Hum Dev 2009; 40: 609-20; http://dx.doi.org/10.1007/ s10578-009-0147-8

30. Dinan TG, Majeed T, Lavelle E, et al. Blunted serotonin-mediated activation of the hypothalamicpituitary-adrenal axis in chronic fatigue syndrome. Psychoneuroendocrinology 1997; 22: 261-7; http://dx.doi.org/10.1016/S0306-4530(97)00002-4

31. Johnson SK, DeLuca J. Chronic fatigue syndrome and the brain. In: DeLuca J (ed). Fatigue as a Window to the Brain. Cambridge, MA: MIT Press, 2005

32. Segal TY, Hindmarsh PC, Viner RM. Disturbed adrenal function in adolescents with chronic fatigue syndrome. J Pediatr Endocrinol Metab 2005; 18: 295-301; http://dx.doi.org/10.1515/ JPEM.2005.18.3.295

33. Smith AK, White PD, Aslakson E, et al. Polymorphisms in genes regulating the HPA axis associated with empirically delineated classes of unexplained chronic fatigue. Pharmacogenomics 2006; 7 : 387-94; http://dx.doi.org/10.2217/14622416.7.3.387

34. Jerjes WK, Cleare AJ, Wessely S, et al. Diurnal patterns of salivary cortisol and cortisone output in chronic fatigue syndrome. J Affect Disord 2005; 87: 299-304; http://dx.doi.org/10.1016/j. jad.2005.03.013

35. Kavelaars A, Kuis W, Knook L, et al. Disturbed neuroendocrine-immune interactions in chronic fatigue syndrome. J Clin Endocrinol Metab 2000; 85: 692-6; http://dx.doi.org/10.1210/jc.85.2.692

36. Torres-Harding SR, Sorenson M, Jason L, et al. The associations between basal salivary cortisol and illness symptomatology in chronic fatigue syndrome. J Appl Biobehav Res 2008; 13: 157-80; http://dx.doi.org/10.1111/j.1751-9861.2008.00033.x

37. Mathew SJ, Coplan JD, Goetz RR, et al. Differentiating depressed adolescent $24 \mathrm{~h}$ cortisol secretion in light of their adult clinical outcome. Neuropsychopharmacology 2003; 28: 1336-43; http://dx.doi. org/10.1038/sj.npp.1300184

38. Miike T, Tomoda A, Jhodoi T, et al. Learning and memorization impairment in childhood chronic fatigue syndrome manifesting as school phobia in Japan. Brain \& Development 2003; 25: 367-9

39. Glaser R, Padgett DA, Litsky ML, et al. Stress-associated changes in the steady-state expression of latent Epstein-Barr virus: implications for chronic fatigue syndrome and cancer. Brain Behav Immun 2005 19: 91-103; http://dx.doi.org/10.1016/j.bbi.2004.09.001

40. Pace TW, Mletzko TC, Alagbe O, et al. Increased stress-induced inflammatory responses in male patients with major depression and increased early life stress. Am J Psychiatry 2006; 163: 1630-3; http://dx.doi.org/10.1176/appi.ajp.163.9.1630

41. Nater UM, Youngblood LS, Jones JF, et al. Alterations in diurnal salivary cortisol rhythm in a population-based sample of cases with Chronic Fatigue Syndrome. Psychosomatic Medicine 2008; 70: 298-305; http://dx.doi.org/10.1097/PSY.0b013e3181651025 
42. Sorenson, M, Jason, L, Lerch, A, et al. The production of Interleukin-8 is increased in plasma and peripheral blood mononuclear cells of patients with fatigue. Neuroscience \& Medicine 2012; 3: 47-53

43. Moss RB, Mercandetti A, Vojdani A. TNF-alpha and chronic fatigue syndrome. J Clin Immunol 1999; 19: 314-6; http://dx.doi.org/10.1023/A:1020595709352

44. Kerr JR, Petty R, Burke B, et al. Gene expression subtypes in patients with chronic fatigue syndrome/myalgic encephalomyelitis. Journal of Infectious Diseases 2008; 197: 1171-1184; http://dx.doi. org/10.1086/533453

45. Landmark-Høyvik $\mathrm{H}$, Reinertsen $\mathrm{KV}$, Loge $\mathrm{JH}$, et al. The genetics and epigenetics of fatigue. $P M$ $R$ 2010; 2: 456-65

46. Saiki T, Kawai T, Morita K, et al. Identification of marker genes for differential diagnosis of chronic fatigue syndrome. Molecular Medicine 2008; 14: 599-607; http://dx.doi.org/10.2119/2007-00059. Saiki

47. Rajeevan MS, Smith AK, Dimulescu I, $t$ al. Glucocorticoid receptor polymorphisms and haplotypes associated with chronic fatigue syndrome. Genes, Brain, \& Behavior 2007; 6: 167-176; http:// dx.doi.org/10.1111/j.1601-183X.2006.00244.x

48. Cleare AJ, Heap E, Malhi GS, et al. Low-dose hydrocortisone in chronic fatigue syndrome: A randomized crossover trial. The Lancet 1999; 353: 455-8; http://dx.doi.org/10.1016/S01406736(98)04074-4

49. McKenzie R, O'Fallon A, Dale J, et al. Low-dose hydrocortisone for treatment of chronic fatigue syndrome: Comparison with chronic fatigue syndrome. American Behavior Medicine 1998; 24: 106-112

50. Chalder T, Tong J, Deary V. Family cognitive behavior therapy for chronic fatigue syndrome: An uncontrolled study. Arch Dis Child 2002; 86: 95-7; http://dx.doi.org/10.1136/adc.86.2.95

51. Viner R, Gregorowski A, Wine C, et al. Outpatient rehabilitative treatment of chronic fatigue syndrome. Arch Dis Child 2004; 89: 615-9; http://dx.doi.org/10.1136/adc.2003.035154

52. Denborough P, Kinsella S, Stevens J, et al. Evaluation of a multidisciplinary inpatient rehabilitation programme for adolescents with chronic fatigue syndrome. Australian Psychiatry 2003; 11: 319-24; http://dx.doi.org/10.1046/j.1440-1665.2003.00559.x

53. Wright B, Ashby B, Beverly D, et al. A feasibility study comparing two treatment approaches for chronic fatigue syndrome in adolescents. Arch Dis Child 2005; 90: 369-372; http://dx.doi. org/10.1136/adc.2003.046649

54. Stulemeijer, M, de Jong LWAM, Fiselier TJW, et al. Cognitive behaviour therapy for adolescents with chronic fatigue syndrome: A randomized controlled trial. BMJ 2004; 330: 14; http://dx.doi. org/10.1136/bmj.38301.587106.63

55. Knoop H, Stulemeijer M, de Jong LW, et al. Efficacy of cognitive behavioural therapy for adolescents with chronic fatigue syndrome: long-term follow-up of a randomized, controlled trial. Pediatrics 2008; 121: e619-e625; http://dx.doi.org/10.1542/peds.2007-1488

56. Prins JB, Bleijenberg G, Bazelmans E, et al. Cognitive behavior therapy for chronic fatigue syndrome: A multicenter randomized controlled trial. The Lancet 2001; 357: 841-7; http://dx.doi. org/10.1016/S0140-6736(00)04198-2

57. White PD, Goldsmith KA, Johnson AL, et al, on behalf of the PACE trial management group. Comparison of adaptive pacing therapy, cognitive behaviour therapy, graded exercise therapy, and specialist medical care for chronic fatigue syndrome (PACE): A randomised trial. The Lancet 2011; 377: 823-36; http://dx.doi.org/10.1016/S0140-6736(11)60096-2

58. Vercoulen JH, Swanink CM, Galama JM, et al. The persistence of fatigue in chronic fatigue syndrome and multiple sclerosis: Development of a model. Journal of Psychosomatic Research 1998; 45: 507-17; http://dx.doi.org/10.1016/S0022-3999(98)00023-3 
59. Song S, Jason LA. A population-based study of chronic fatigue syndrome (ME/CFS) experienced in differing patient groups: An effort to replicate Vercoulen et al's model of ME/CFS. J Ment Health 2005; 14: 277-89; http://dx.doi.org/10.1080/09638230500076165

60. Price JR, Mitchell E, Tidy E, et al. Cognitive behaviour therapy for chronic fatigue syndrome in adults. Cochrane Database Syst Rev 2008; 3: CD001027

61. Action for ME. Preliminary Report. The severely affected 2001

62. ME Essential. Gawcott, England: ME Association, 2009

63. Action for ME and Association of Young People with ME. What progress?, 2008. Available at: http://www.afme.org.uk/res/img/resources/Survey\%20Summary\%20Report\%202008.pdf

64. Roberts AD, Paradopoulos AS, Wessely S, et al. Salivary cortisol output before and after cognitive behavioural therapy for chronic fatigue syndrome. J Affect Disord 2008; 115: 280; http://dx.doi. org/10.1016/j.jad.2008.09.013

65. McLean A, Coutts K, Becker WJ. Pacing as a treatment modality in migraine and tension-type headache. Disability \& Rehabilitation 2008; 1-8. Online version. Available at http://informahealthcare.com/doi/abs/10.3109/09638288.2011.610496

66. Goudsmit EM. The psychological aspects and management of chronic fatigue syndrome. $\mathrm{PhD}$ thesis. London: Brunel University, UK, 1996. Available from Ethos: http://ethos.bl.uk/Home.do

67. Goudsmit EM, Nijs J, Jason LA, et al. Pacing as a strategy to improve energy management in myalgic encephalomyelitis/chronic fatigue syndrome: a consensus document. Disability and Rehabilitation 2011; 34: 1140-7; http://dx.doi.org/10.3109/09638288.2011.635746

68. Goudsmit EM, Howes S. Pacing: a strategy to improve energy management in chronic fatigue syndrome. Health Psychology Update 2008; 17: 46-52

69. Jason LA, Torres-Harding S, Friedberg F, et al. Non-pharmacologic interventions for ME/CFS: a randomized trial. J Clin Psychol in Medical Settings 2007; 14: 275-96; http://dx.doi.org/10.1007/ s10880-007-9090-7

70. Jason LA, Benton M, Torres-Harding S, et al. The impact of energy modulation on physical functioning and fatigue severity among patients with ME/CFS. Patient Education and Counseling 2009; 77: 237-41; http://dx.doi.org/10.1016/j.pec.2009.02.015

71. Brown M, Khorana N, Jason LA. The role of changes in activity as a function of perceived available and expended energy in nonpharmacological treatment outcomes for ME/CFS. J Clin Psychol 2011; 3: 253-60; http://dx.doi.org/10.1002/jclp.20744

72. Brown M, Bell DS, Jason LA, et al. Understanding long-term outcomes of chronic fatigue syndrome. J Clin Psychol 2012; 68: 1028-35; http://dx.doi.org/10.1002/jclp.21880

73. Cairns R, Hotopf M. A systematic review describing the prognosis of chronic fatigue syndrome. Occupational Medicine 2005; 55: 20-31; http://dx.doi.org/10.1093/occmed/kqi013

74. Joyce J, Hotopf M, \& Wessely S. The prognosis of chronic fatigue and chronic fatigue syndrome. Quarterly Journal of Medicine 1997; 90: 223-33; http://dx.doi.org/10.1093/qjmed/90.3.223

75. Arav-Boger R, Spirer Z. Chronic fatigue syndrome: pediatric aspects. Israel Journal of Medical Sciences 1995; 31: 330-4

76. Carter BD, Marshall GS. New developments: diagnosis and management of chronic fatigue in children and adolescents. Current Problems in Pediatrics 1995; 25: 281-93; http://dx.doi. org/10.1016/S0045-9380(06)80057-5

77. Jordan KM, Landis DA, Downey MC, et al. Chronic fatigue syndrome in children and adolescents. Journal of Adolescent Health 1998; 22: 4-18; http://dx.doi.org/10.1016/S1054-139X(97)00212-7

78. Mears CJ, Taylor RR, Jordan KM, et al. Sociodemographic and symptom correlates of fatigue in an adolescent primary care sample. J Adolesc Health 2004; 35: 528-33

79. Marshall GS. Chronic fatigue syndrome. In Kaplan S. (ed). Current therapy in pediatric infectious disease. St. Louis, MO: Mosby-Year Book, 1993 